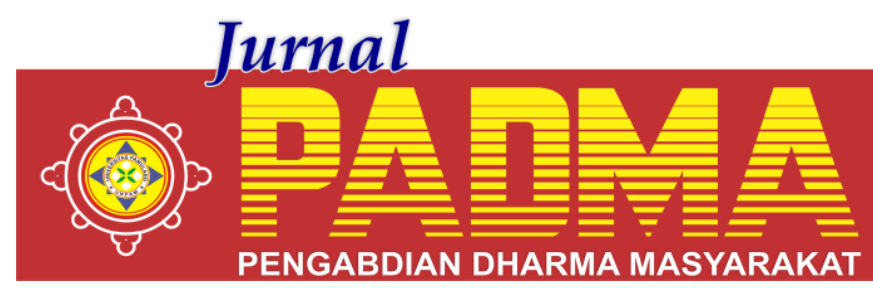

VOLUME I, NOMOR 4, OKTOBER 2021

\title{
PENGENALAN DIGITAL MARKETING, PELATIHAN SOSIAL MEDIA DAN E-COMMERCE DAN MERANCANG KONTEN PEMASARAN YANG BAIK BAGI PELAKU USAHA UMKM DI YAYASAN AMAL BAKTI SUDJONO TARUNO BAKI SUKOHARJO
}

\author{
${ }^{1}$ Sri Wijiastuti, ${ }^{2 *}$ Kurniawati Darmaningrum, ${ }^{3}$ Zandra Dwanita Widodo \\ Universitas Tunas Pembangunan Surakarta, Jawa Tengah, Indonesia \\ *kurniawati.darmaningrum@lecture.utp.ac.id
}

\begin{abstract}
Abstrak
Pertumbuhan untuk industri e-Commerce di Indonesia diprediksi dapat mencapai sebesar US\$ 130 miliar pada tahun 2020. Pertumbuhan industri e-commerce per tahun yang dapat mencapai 50 persen dan ditambah dengan pengguna smartphone yang terus bertumbuh merupakan peluang yang sangat besar untuk pelaku UMKM dalam meningkatkan penjualan produk mereka. Digital marketing memungkinkan pembeli memperoleh seluruh informasi mengenai produk dan bertransaksi melalui internet, dan memungkinkan penjual untuk memantau dan menyediakan kebutuhan serta keinginan calon pembeli tanpa batasan waktu dan geografis. Media promosi digital diharapkan menjadi pilihan yang efektif untuk pelaku UMKM dalam mengembangkan bisnis dan menjangkau pasar nasional maupun internasional. Media promosi konvensional yang membutuhkan banyak biaya dan jauh lebih rumit dengan sendirinya tidak lagi menjadi perhatian utama bagi pelaku UMKM karena adanya digital marketing. Pelaku UMKM dengan menggunakan e-commerce atau marketplace dapat menjangkau calon costumer yang lebih luas dan lebih banyak, tidak hanya terbatas pada suatu wilayah promosi saja. Digital marketing dan ecommerce atau marketplace dapat menjangkau wilayah yang lebih luas dibanding pemasaran secara konvensional, sehingga hal ini menjadi pilihan yang solutif untuk ekspansi bisnis
\end{abstract}

Kata Kunci: UMKM, Digital Marketing, E-Commerce

\section{Abstract}

Growth for the e-commerce industry in Indonesia is predicted to reach US\$130 billion by 2020. The annual growth of the e-commerce industry which can reach 50 percent and coupled with smartphone users who continue to grow is a huge opportunity for MSME players to increase sales of their products. Digital marketing allows buyers to obtain all information about products and transact via the internet, and allows sellers to monitor and provide for the needs and desires of potential buyers without time and geographical restrictions. Digital promotion media is expected to be an effective choice for MSME players in developing business and reaching national and international markets. Conventional promotional media that require a lot of money and are much more complicated by themselves are no longer a major concern for MSME actors because of digital marketing. MSME actors by using e-commerce or marketplaces can reach a wider and more potential customer, not only limited to a promotional area. Digital marketing and e-commerce or marketplaces can reach a wider area than conventional marketing, so this is a solution choice for business expansion.

Keywords: MSME, Digital Marketing, E-Commerce

\section{PENDAHULUAN}

Media komunikasi yang dapat digunakan Pelaku Usaha Kecil Menengah (UMKM) untuk mempromosikan usahanya salah satunya adalah komunikasi media internet. Pelaku Usaha Kecil Menengah (UMKM) dapan menggunakan dan memanfaatkan e-commerce dan marketplace yang memberikan peluang yang lebih besar untuk bisa mengekspansi penjualan produk mereka melalui media digital. Pelaku UMKM perlu dan penting untuk bisa memanfaatkan bermacam cara untuk melakukan promosi dan meningkatkan penjualan produk mereka, salah satunya dengan memanfaatkan peluang yang ada. Namun, dilihat berdasarkan data yang sudah dirilis oleh Kementrian Koperasi dan Usaha Kecil Menengah (Kemenkop UMKM), baru sekitar 3.79 juta pelaku UMKM yang sudah memanfaatkan dan mengggunakan platform online dalam memasarkan produk- 
produknya. Jumlah ini hanya berkisar 8 persen dari total pelaku UMKM di Indonesia, yaitu 59.2 juta (www.cnnindonesia.com). Pertumbuhan industri e-Commerce Indonesia diprediksi mencapai sebesar US\$ 130 miliar pada tahun 2020. Pertumbuhan industri e-commerce per tahun yang mencapai 50 persen ditambah dengan pengguna smartphone yang terus bertumbuh merupakan peluang yang sangat besar untuk pelaku UMKM dalam meningkatkan penjualan produk mereka.

Salah satu penelitian yang telah dilakukan oleh Pradiani (2018) menunjukkan bahwa Ibu-ibu PKK sangat merasakan manfaat yang begitu besar dengan menggunakan sosial media sebagai sarana kegiatan pemasaran untuk hasil industri rumahannya. Hal ini memberikan indikasi bahwa digital marketing sangat potensial untuk dikembangkan. Pelaku UMKM dapat memanfaatkan sosial media untuk mempromosikan produknya. Sejalan dengan pernyataan Moriansyah (2015) berdasarkan alasan atau motivasi pemasar menggunakan media sosial (antecedants) dan target dari progam pemasaran yang dapat diraih dengan menggunakan media sosial. Pelanggan akan mendapatkan stimulus dari promosi-promosi yang dilakukan pemasar, keluarga, teman, atau komunitas online, untuk menjadi aktif berbelanja.

Digital marketing memberikan kesempatan untuk pembeli agar dapat memperoleh seluruh informasi mengenai produk dan bertransaksi melalui internet, dan memungkinkan penjual memantau dan menyediakan kebutuhan serta keinginan calon pembeli tanpa batasan waktu dan geografis. Media promosi digital diharapkan menjadi pilihan yang efektif untuk pelaku UMKM dalam mengembangkan bisnis dan menjangkau pasar nasional maupun internasional. Media promosi konvensional yang banyak membutuhkan biaya dan jauh lebih rumit dengan sendirinya tidak lagi menjadi perhatian utama bagi pelaku UMKM karena adanya digital marketing. Pelaku UMKM, dengan menggunakan e-commerce atau marketplace dapat menjangkau calon costumer yang lebih luas dan lebih banyak, tidak hanya terbatas pada suatu wilayah promosi saja. Digital marketing dan e- commerce atau marketplace dapat menjangkau wilayah yang lebih luas dibanding pemasaran secara konvensional, sehingga hal ini menjadi pilihan yang solutif untuk ekspansi bisnis.

Pemasaran dengan sosial media dan ecommerce saat ini sedang meningkat pesat dikarenakan pandemi yang membuat sulitnya peluang untuk berjualan secara offline. Digital marketing menjadi alternatif yang bisa digunakan pelaku usaha untuk memasarkan produk mereka, membuka peluang baru, serta meningkatkan penjualan. Pengetahuan tentang digital marketing tidak hanya mengenai pembelian dan penjualan produk saja, tetapi juga mencakup promosi dan pemasaran produk yang lebih luas. Sementara itu masih banyak masyarakat yang menggunakan media internet tidak secara maksimal sehingga alangkah bijaknya bagi kita untuk mengenalkan mereka bagaimana cara penggunaan digital marketing dengan baik. Permasalahan yang ada di Yayasan Amal Bakti Sudjono Taruno adalah pelaku UMKM belum mengetahui bagaimana penggunaan digital marketing dengan baik dan belum bisa membuat konten yang menarik bagi produk UMKM mereka. Sehingga pelatihan ini diharapkan memberikan wawasan dan pengetahuan baru bagi mereka.

\section{METODE}

Metode pelaksaan kegiataan dilakukan di Yayasan Amal Bakti Sudjono Taruno dengan mengikuti protokol kesehatan untuk mencegah penyebaranCovid-19. Peserta pelatihan dibatasi jumlahnya dan dipastikan mengikuti seluruh protokol kesehatan yang ditetapkan. Metode ceramah dipilih untuk memberikan materi yang disampaikan, kemudia disambung dengan tanya jawab dan praktek. Pelatihan digital marketing ini akan diselenggarakan dengan tahapan-tahapan sebagai berikut :

1. Pengenalan digital marketing

2. Pelatihan penggunaan sosial media dan ecommerce

3. Pelatihan membuat konten pemasaran untuk produk yang dipasarkan

\section{HASIL DAN PEMBAHASAN}

Hasil pelaksanaan kegiatan secara garis besar terdiri dari ketercapaian target 
jumlah peserta, ketercapaian tujuan kegiatan, serta ketercapaian target materi yang telah direncanakan. UMKM yang dibimbing dalam kegiatan ini adalah Yayasan Amal Bakti Sudjono Taruno, yayasan ini memiliki usaha jamu tradisional yang dikemas dalam kemasan bubuk dan dipasarkan di Kota Solo dan sekitarnya. Jumlah peserta yang hadir dalam kegiataan ini berjumlah 55 orang yang merupakan pelaku usaha jamu di yayasan ini. Pandemi membuat masyarakat semakin sadar akan kesehatan mereka, hal ini menyebabkan jamu semakin dicari untuk dikonsumsi. Ini membuka peluang bagi UMKM khususnya dalam bidang jamu untuk mengembangkan pasar mereka. Digital marketing dan ecommerce dapat membantu usaha ini untuk mengembangkan pasarnya. Pelatihan ini diharapkan mampu membantu mereka memahami dam mempersiapkan diri dan usahanya agar sukses dalam menggunakan digital marketing dan ecommerce.

Tujuan diadakannya pelatihan ini adalah agar dapat membantu mengembangkan peluang usaha di yayasan ini sehingga menjadi peluang usaha yang dapat menghasilkan keuntungan secara maksimal, maka dapat disimpulkan bahwa tujuan kegiatan ini dapat tercapai. Hal ini ditunjukkan dengan antusiasme para peserta dalam bertanya dan sharing ilmu selama kegiatan tanya jawab. Ketercapaian target materi pada kegiatan PKM ini cukup baik karena materi yang disampaikan sudah disesuaikan dengan kondisi lapangan tempat diadakannya PKM ini. Selain itu materi disampaikan dengan sistem tanya jawab dan diskusi sehingga peserta juga dapat memberikan pertanyaan maupun berbagi pengalaman. Keterlibatan ini penting bagi jalannya PKM agar dapat dipastikan bahwa materi yang diberikan dapat tersampakan maksud dan tujuannya.

\section{PENUTUP}

Berdasar hasil wawancara dengan pelaku UMKM jamu di Yayasan Amal Bakti
Sudjono Taruno permasalahan yang dimiliki oleh pelaku adalah kurangnya pengetahauan tentang digital marketing, penggunaan sosial media dan e-commerce, dan cara pembuatan konten pemasaran yang menarik bagi konsumen. Oleh karena itu, pelatihan ini dibuat dengan tahap-tahap sebagai berikut: pengenalan digital marketing, pelatihan penggunaan sosial media dan e-commerce, dan pelatihan membuat konten pemasaran untuk produk yang dipasarkan. Setelah dilakukan pelaksanaan kegiatan PKM ini, dirasakan perlu dilakukan kegiatan pendampingan dan pemberian motivasi kepada pelaku usaha secara terus menerus agar manfaat dari pelatihan ini dapat dirasakan oleh pelaku UMKM.

\section{DAFTAR PUSTAKA}

Ajimat, A., et al. (2020). Berwirausaha Memanfaatkan Media Sosial Pada Daerah Sepatan. ADI Pengabdian Kepada Masyarakat, 1(1), 69-76.

Ayuwuragil, Kusti. (2017). Kemenkop UKM: 3,79 Juta UMKM Sudah Go Online. https://www.cnnindonesia.com/ekon omi/20171115161037-78255819/kemenkop-ukm-379-jutaumkm-sudah-go-online. Diakses Januari 2021.

La Moriansyah. 2015. Pemasaran Melalui Media Sosial: Antecedents Dan Consequences. Vol 19, No 3 (2015): Jurnal Penelitian Komunikasi dan Opini Publik. Fakultas Ekonomi dan Bisnis, Universitas Indonesia, Indonesia.

Nurhayati, et al (2018). Pelatihan Pembukuan Di UKM Sumpia Chantika Dewi Cimindi Cimahi. Laporan Program Kepakaran Fisip Unpas Pengabdian Kepada Masyarakat Tahun Akademik 2016/2017, 1-22.

T Pradiani, D Damara. (2018). pengaruh Website Dan Kesadaran Merek Terhadap Keputusan Pembelian Produk Yang Dijual Di Mataharimall. Com. Jurnal EKSIS Vol 10 (2). 